\title{
Instrumental Climate Data
}

\section{Reinhard BöHM}

Central Institute for Meteorology and Geodynamics, Vienna, Austria; boehm@zamg.ac.at

Instrumental data form the necessary basis for climate reconstructions. The data are used for calibration in proxy reconstructions and are usually considered to be "true" climate information by proxy specialists. However, before applying instrumental data to proxy climate reconstructions, a number of questions should be addressed: To what extent do instrumental data reflect real climate? For which regions of Europe does well-tested and homogenized instrumental climate information exist? How long are the existing instrumental series and what is their spatial density? Last but not least, coverage by different climate parameters should also be taken into account. That is, "climate" reconstructions should be more than single-variable analyses. In most cases, climate is represented by temperature alone. Precipitation is sometimes also included but very rarely is the whole climate system analyzed.

Experience with instrumental climate reconstruction in Alpine areas shows that homogenization is indispensable for extracting the real climate signal from nonclimatic noise. Non-climatic noise is caused by a number of factors, such as relocation, and changes in measuring technology, instrument installation and observation time, among others. The uncertainty

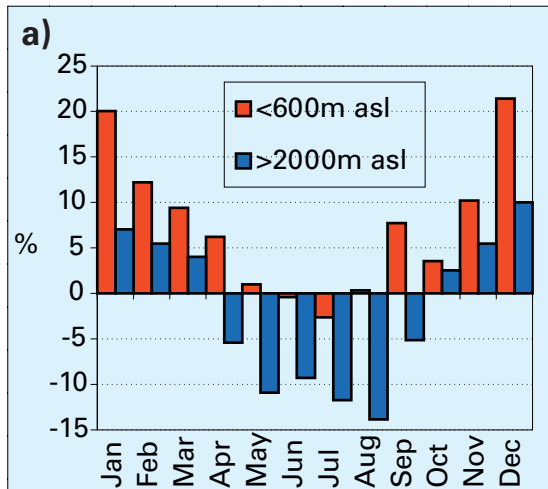

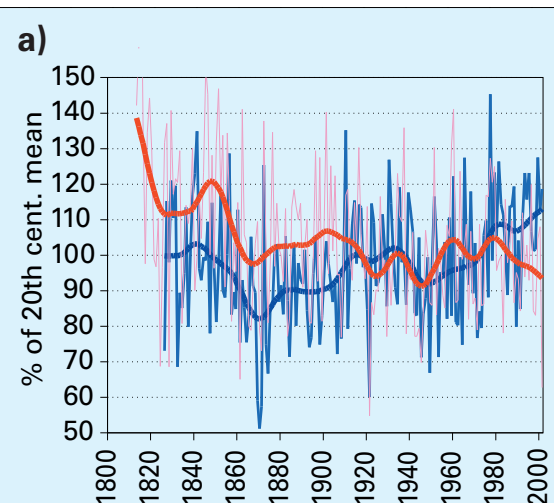

b)

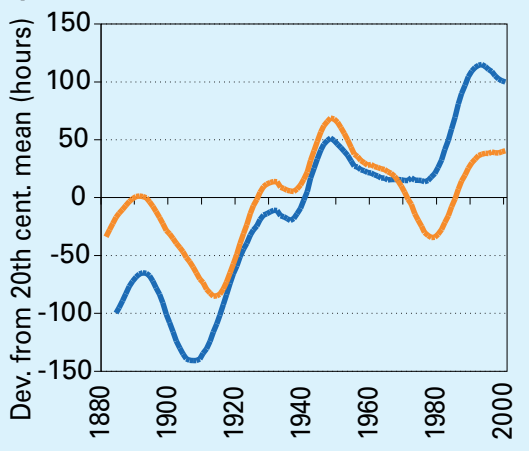

Figure 2: Two examples of the spatial variability of long-term climate trends.

(a) Long-term annual precipitation totals (single years and 30 years smoothed) for a grid point in SE-France $\left(4 E-46 \mathrm{~N}\right.$, blue) and one in N-Italy $(10 E-46 N)$, both relative to the $20^{\text {th }}$ century mean. (b) Long-term annual sunshine duration in the Eastern Alps (30 years smoothed) for high (>2000m, blue) and low (<600m, yellow) elevation sites.

is not made random simply by combining a large number of series together, since in many cases there are systematic biases in the original series. Figure 1 shows two examples of such systematic offsets in climatic time series-one typical of recent decades, one of the $19^{\text {th }}$ century. While homogenization is valuable, poor quality homogenization can erroneously import climate information from remote regions. It should therefore be undertaken with care, using mathematical tests together with information about station history (meta-data) and be carried out in smaller sub-regions with a dense network of highly correlated series. For an overview on homogenization see Peterson et al. (1998).

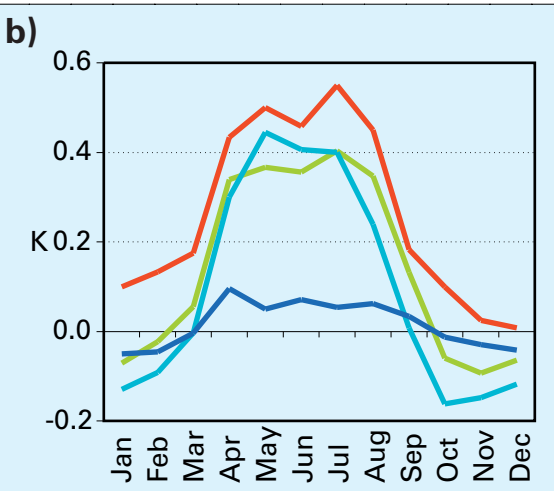

Figure 1: Two examples of systematic offsets in instrumental climatic time series in Central Europe. (a) Sunshine duration offset (new minus old in percent of monthly totals) in the 1980s due to automation in the Austrian network (red: low elevation sites, blue: high elevation sites). (b) Temperature offset (new minus old in ${ }^{\circ} \mathrm{C}$ ) in the late $19^{\text {th }}$ century for four typical surroundings due to changes in observation time (red: urban, green: extra-alpine rural, light blue: inner-alpine $<1000 m$ asl., dark blue: inner-alpine >2000m asl.)
Two European sub-regions serve to illustrate "close to ideal" instrumental climate variability datasets. They show the number of inhomogeneities that are detectable and removable, the average length of homogeneous sub-intervals for the different climate parameters, and to what extent such highdensity regional datasets differ from existing large-scale datasets. These sub-regions are the "Larger Fennoscandian Region" (NACD dataset, e.g. Moberg and Alexandersson, 1997; Hanssen-Bauer and Nordli, 1998) and the "Greater Alpine Region" (ALOCLIM and ALPCLIM datasets, e.g. Auer et al., 2001; Böhm et al., 2001). Both are "multiple", "long-term" and "dense", much time has been invested in homogenization of both instrumental series, and both regions are rich in proxy data sources for paleoclimate reconstructions. Studies of these regional high-density datasets (typical mean site distances of 30 to $100 \mathrm{~km}$ ) show that existing global-scale datasets (e.g. Jones, 1994; Vose et al., 1993) are deficient when resolving meso-scale variability patterns. Paleo-climatologists should pay attention to this fact since most of the proxy sources react to local to meso-scale climate and not to continental to globalscale changes. Two examples from the European Alps illustrate that there is not only variability in time 


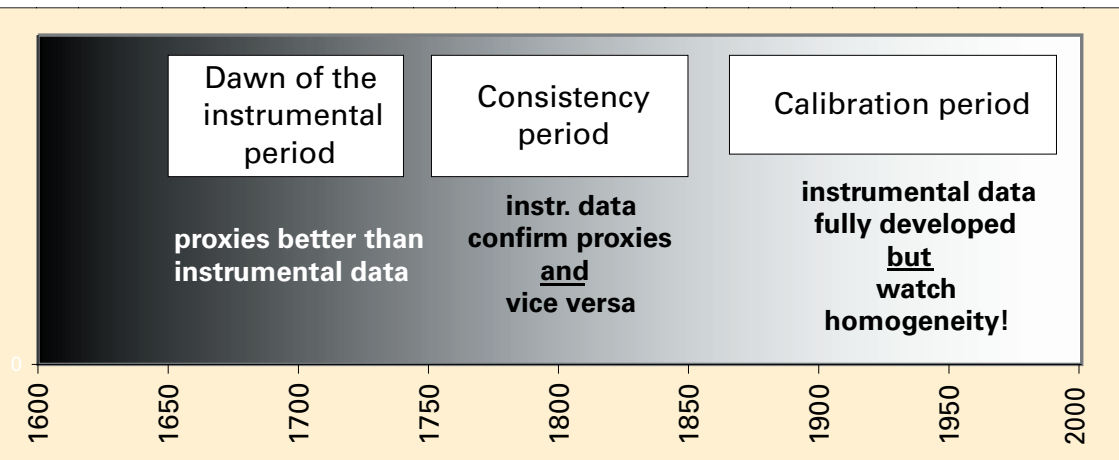

Figure 3: Development of the potential of instrumental climate data for paleo-climate reconstructions.

but also considerable variability in space-horizontally (Fig. 2 left) and vertically (Fig. 2 right).

Figure 3 presents a timeline that summarizes our conclusions on the quality, availability and potential of instrumental data for the reconstruction of climate. There is no question that before the mid$18^{\text {th }}$ century the very rare instrumental information that existed is inferior to high-quality reconstructions based on proxies. The real calibration period started as late as the second half of the $19^{\text {th }}$ century. Since then, well-homogenized and spatially dense instrumental information has been available to calibrate proxy data. For the one hundred years in between, both sources (instrumental and proxy) are reliant on each other, with only a combination of different sources providing reasonable information about past climate variability. That period may therefore best be called the "consistency period".

\section{REFERENCES}

Auer, I., Böhm, R. and Schöner, W., 2001: Austrian long-term climate 1767-2000 - Multiple instrumental climate time series from Central Europe. Österr. Beitr. Zu Meteorologie und Geophysik 25 147 pp (plus Data- and Metadata-CD)

Böhm, R., Auer, I., Brunetti, M., Maugeri, M., Nanni, T. and Schöner, W., 2001: Regional temperature variability in the European Alps 1760-1998 from homogenized instrumental time series. International Journal of Climatology 21: 1779-1801

Jones P.D., 1994: Hemispheric surface air temperature variations: A reanalysis and an update to 1993. Journal of Climate 7: 1794-1802

Moberg, A. and Alexandersson, H., 1997: Homogenization of Swedish temperature data. Part II: Homogenised gridded air temperature compared with a subset of global air temperature since 1861 International Journal of Climatology 17: 35-54

Peterson, T.C., Easterling, D.R., Karl, T.R., Groisman, P., Auer, I., Böhm, R., Plummer, N., Nicholis, N. Torok, S., Vincent, L., Tuomenvirta, H., Salinger, J., Førland, E.J., Hanssen-Bauer, I., Alexandersson, H., Jones, P. and Parker, D., 1998: Homogeneity Adjustments of In Situ Atmospheric Climate Data: A Review. International Journal of Climatology 18 1493-1517

For full references please consult:

www.pages-igbp.org/products/newsletters/ref2003_2.html

\title{
Climate and Environmental Reconstructions from Scandinavian Varved Lake Sediments
}

\author{
Antti E.K. 0jala ${ }^{1}$, Matti SaAnisto ${ }^{1}$ and Ian F. Snowball ${ }^{2}$
}

1Geological Survey of Finland; antti.ojala@gsf.fi; matti.saarnisto@gsf.fi

2Quaternary Geology, Lund University, Sweden; ian.snowball@geol.lu.se

\section{Introduction}

Annually resolved proxy records, such as varved lake sediments, are important archives of past climate variability and environmental change. The primary strength of any varved archive is that it contains a continuous and inherent calendar year timescale that forms a temporal framework for paleoenvironmental reconstruction. In addition, many physical, chemical and biological parameters can be used to accurately infer fluxes. The structure and composition of varves are governed by a multitude of interacting factors in different sedimentary environments that, in the best cases, can be related to external forcing factors and subsequently interpreted as records of regional climate change (e.g. Hughen et al., 2000).

The contemporary annual climate in Fennoscandia has strong

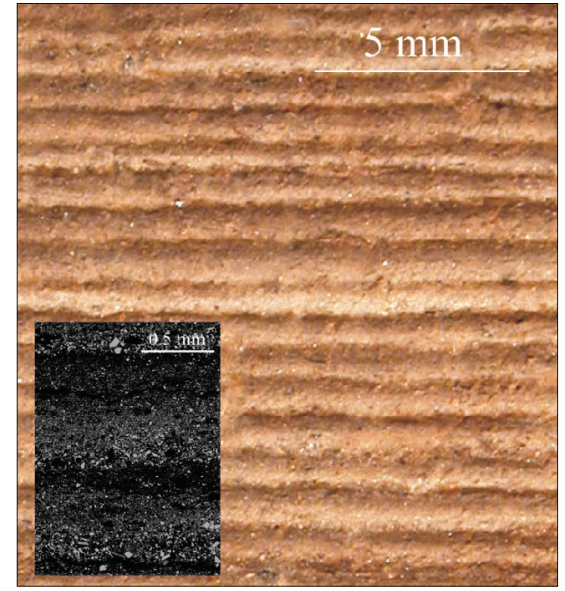

Figure 1: Images of Lake Nautajärvi (central Finland) clastic-organic nonglacial varves at $A D 200$ taken from the fresh sediment surface (left) and thin-section, using a backscattered mode of surface scanning electron microscope (right).

seasonality, which causes several months of ice cover on lakes, peak floods during the spring snowmelt, summer (and winter) stratification of the water column, algal blooms and occasional autumn storms.
This myriad of factors is the principal cause of distinct rhythmic sedimentation and of the formation and preservation of varves in lakes (Renberg, 1982; Ojala et al., 2000, Zillén et al., in press). Varves in small to mid-sized lakes in Finland and Sweden typically appear as clastic-biogenic couplets (Fig. 1) (Petterson, 1996; Ojala et al., 2000), which sometimes cover the entire past glacial history of the basin, up to 10,000 years or more. A typical Fennoscandian lake varve is composed of an allochthonous fine-grained minerogenic layer deposited as a result of the spring snowmelt, grading into an organic summer layer formed by primary productivity and a thin dark-colored layer composed of fine-grained organic matter that settles during the winter when the lake is ice-covered (Renberg, 1982). In many cases, the varves are best seen after oxidation 